\title{
ERRATUM
}

\section{Erratum to: Efficacy and Safety of Tapentadol Prolonged Release for Chronic Osteoarthritis Pain and Low Back Pain}

Bernd Lange · Brigitte Kuperwasser · Akiko Okamoto · Achim Steup · Thomas Häufel · Judy Ashworth · Mila Etropolski

(c) 2010 Springer Healthcare

Erratum to: Lange B, et al. Efficacy and safety of tapentadol prolonged release for chronic osteoarthritis pain and low back pain. Adv Ther. 2010;27(6):381-399.

The publishers would like to apologize for an error that occurred in the publication of the above-mentioned article, by Bernd Lange and colleagues, in which the Y-axis of Figure 3 has been compromised during the production process.

We have attached the revised figure below, for clarification.

Figure 3. Mean change from baseline in average pain intensity over time using the last observation carried forward (intentto-treat population).

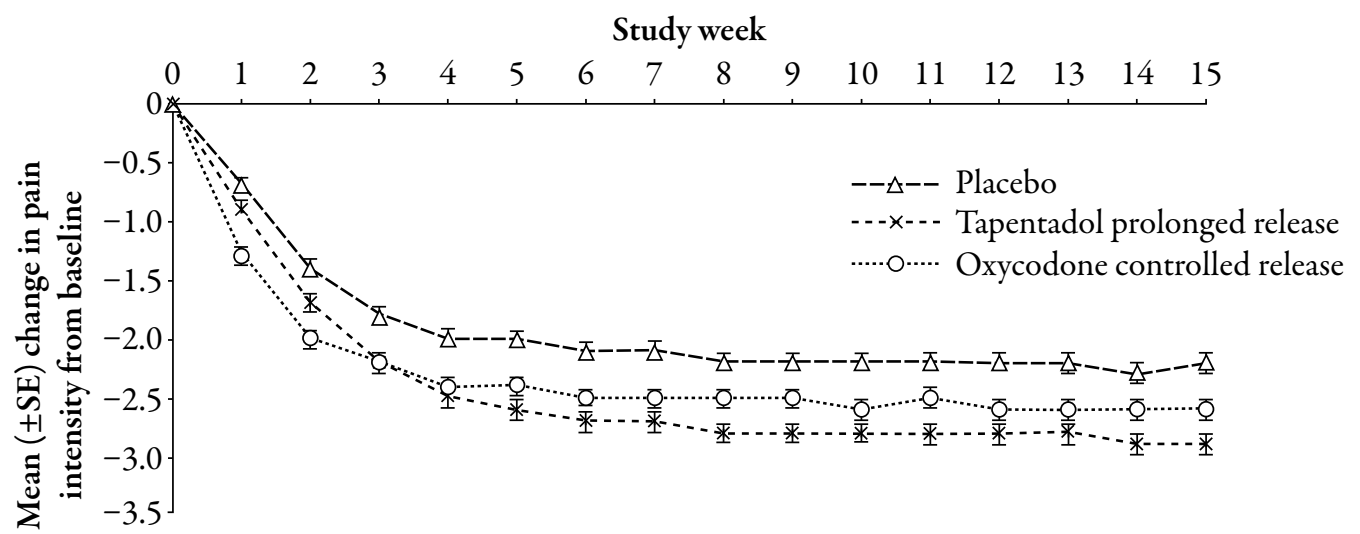

